\title{
REVIEW
}

\section{Autonomic function as a missing piece of the classification of Paralympic athletes with spinal cord injury}

\author{
PB Mills ${ }^{1,2}$ and A Krassioukov ${ }^{1,3,4}$ \\ ${ }^{1}$ Division of Physical Medicine and Rehabilitation, Department of Medicine, University of British Columbia, Vancouver, \\ British Columbia, Canada; ${ }^{2}$ School of Population and Public Health, University of British Columbia, Vancouver, British Columbia, \\ Canada; ${ }^{3}$ International Collaboration on Repair Discoveries (ICORD), University of British Columbia, Vancouver, British Columbia, \\ Canada and ${ }^{4}$ GF Strong Rehabilitation Centre, Vancouver Costal Health, Vancouver, British Columbia, Canada
}

\begin{abstract}
Objective: When someone suffers a spinal cord injury $(\mathrm{SCl})$ many organs, including those of the cardiovascular (CV) system, cease to be controlled by the autonomic nervous system (ANS). Response to physical activity fails to meet the needs of the body and typically results in low blood pressure (BP), and in turn, reduced endurance and performance. This study examines the effect of SCI on the ANS of elite athletes and possible effect on their CV functions and ultimately their performance. The study also provides input on evidence of boosting and the current classification system. Finally, authors are exploring a possibility for future research in assessing whether consideration of ANS function would strengthen current Paralympic classification systems.

Study design: MEDLINE, SportDiscus, Embase databases and the official Paralympic website were reviewed. In total, 60 manuscripts and five website documents were reviewed.

Result: Athletes with high-level SCI affecting the ANS have limited ability to regulate their heart rate and BP in response to exercise. According to current Paralympic classification systems, these athletes are grouped with competitors who have similar motor control but intact ANS, thereby potentially putting them at a disadvantage within their own classification category. High-level SCl athletes with ANS dysfunction are also the only athletes who experience episodes of autonomic dysreflexia (AD). Whereas AD is a state of uninhibited sympathetic discharge, it is called 'boosting' when intentionally induced during competition. Boosting has been shown to improve sporting performance but can also cause serious complications due to extreme rises in BP. Therefore, boosting has been banned by the International Paralympic Committee (IPC). Despite this ban some elite high-level SCI athletes continue to boost. The IPC recognizes that the current classification systems are not the gold standard and further work is needed to create a more evidence-based classification.

Conclusions: Further research is needed to determine if the inclusion of ANS parameters contributes to strengthen classifications systems in Paralympic sports. This includes the development of a simple, valid and reliable bedside assessment of autonomic function that can be used to reliably compare athletes with or without ANS dysfunction thereby enabling further research into the isolated effect of ANS dysfunction on sporting performance. Researchers who are studying individuals with $\mathrm{SCl}$, and who have CV parameters as their outcomes, should ensure a homogenous study group by the presence or absence of ANS function in addition to level of lesion so as to eliminate the potential for confounding variables that lead to inaccurate interpretation of results.
\end{abstract}

Spinal Cord (2011) 49, 768-776; doi:10.1038/sc.2011.2; published online 1 March 2011

Keywords: spinal cord injury; cardiovascular; autonomic dysreflexia; performance; boosting

\section{Introduction}

An even playing field for athletes is a major intention of the classification system developed for Paralympic sports. ${ }^{1}$

Correspondence: $\operatorname{Dr}$ A Krassioukov, Division of Physical Medicine and Rehabilitation, International Collaboration on Repair Discoveries, ICORDBSCC, University of British Columbia, 818 West 10th Avenue, Vancouver, British Columbia, Canada V5Z $1 \mathrm{M} 9$

E-mail: krassioukov@icord.org

Received 5 July 2010; revised 27 November 2010; accepted 29 November 2010; published online 1 March 2011
The International Paralympic Committee (IPC) recognizes that the current classification system is not perfect, and that ongoing effort must be made to ensure fair, evidence-based classification. $^{2}$ Classification is very complex and a sportspecific process. However, the primary focus, with the exclusion of the categories for visual or intellectual impairment, is to use remaining or impaired motor control as the defining criterion to group athletes into categories. $^{1}$ 
Exclusive use of motor function for classification may be perceived as a limitation of current Paralympic classification systems as this approach does not take into account conditions that affect the autonomic nervous system (ANS), which is known to control heart rate (HR), blood pressure (BP), and other factors, which could negatively impact sporting performance. ${ }^{3-6}$ This creates a unique challenge for a specific population of Paralympians: athletes who have a spinal cord injury (SCI) and consequently impairment of autonomic control. In all sports, these athletes are grouped together with individuals who have similar motor control but intact ANS, thereby potentially putting them at a disadvantage ${ }^{1}$ Furthermore, among the athletes with SCI there is significant variability of autonomic dysfunctions that are presently not taken into consideration during IPC classification.

To further complicate matters, athletes with SCI who are potentially at a disadvantage due to ANS dysfunction are also the only athletes who are able to 'boost. ${ }^{7}$ Boosting is a state of intentionally induced autonomic dysreflexia (AD) by an athlete during training or competition. ${ }^{8}$ Boosting has been shown to increase sporting performance compared with unboosted states. ${ }^{7,9,10}$ However, there are significant health risks associated with boosting, as an increase in BP during AD can cause serious adverse health events such as intracerebral bleeds, seizures, myocardial ischemia and even death. ${ }^{11-18}$ Therefore the practice of boosting has been banned in the Paralympics. ${ }^{19,20}$

The purpose of this study is to explore the complex issue of the impact of ANS dysfunction in sports for persons with SCI by, (1) describing the effect of SCI on the ANS, (2) reviewing how the current classification system can create disadvantages within the categories that include athletes with SCI affecting the ANS, (3) considering how ANS dysfunction can impact sporting performance during boosted and unboosted states, (4) exploring the evidence on frequency of use of boosting in sport and (5) discussing the IPC's position on the practice of boosting and the current classification system. A review of the existing literature involving athletes with SCI and documentation from the IPC was performed in order to help guide future work in this area.

\section{Methods for literature review}

We conducted a keyword literature search of articles, practice guidelines, and review articles published between 1980 and December 2009 in English and included the internet databases MEDLINE, SportDiscus and EMBASE. The keywords 'spinal cord injury', 'paraplegia' and 'tetraplegia' were combined with 'blood pressure', 'heart rate', 'exercise', 'boosting', 'autonomic dysreflexia' and 'sport performance.' Abstracts were reviewed for identification of information on trained athletes with SCI as subjects. The IPC documents were accessed from the website http://www.paralympic.org.

\section{Effect of $\mathrm{SCl}$ on the ANS}

In order to appreciate the complexity of the current Paralympic classification of athletes, a basic understanding of the effects of SCI on the human body is essential. Injury to the spinal cord is typically associated with loss of motor and sensory functions. However, SCI can also lead to an interruption of pathways of the ANS from its central origins in the brain to the peripheral organ innervation, thus affecting autonomic control of various organs, including those of the cardiovascular (CV) system (Figure 1). 5,6,13,21

The ANS is comprised of both the parasympathetic and sympathetic nervous system. With respect to CV control, the parasympathetic is prominent during restful states and is mediated through the vagus nerve, acting to decrease HR. Vagal control of the heart originates from the medulla and is usually spared following SCI. 5,6,21 The vagus nerve innervates only the heart with no effect to blood vessels. The sympathetic nervous system innervates both the heart muscle and smooth muscles within peripheral blood vessels, and is predominant in times of physiological stress and exercise, acting to increase $\mathrm{HR}$ and BP. ${ }^{5,21}$ Sympathetic innervation to the heart and the majority of blood vessels for the upper extremity originates from the upper thoracic segments (T1-T5); the vasculature beds in the gut and lower extremities are under the control of the more caudal T6-L2 spinal sympathetic neurons. ${ }^{5,22,31,32}$ Injury below T6 tends to spare cardiac and most blood vessel control, whereas SCI above T6 can interrupt supraspinal sympathetic control to the heart, after which spinal circuits become solely responsible for the generation of sympathetic activity below the level of injury. ${ }^{5,6,22}$ For the purpose of this paper, the term 'high-level SCI' will denote an injury above T6. A high-level SCI affecting the ANS results in low resting sympathetic tone below the level of injury, with mostly unopposed parasympathetic (vagal) tone to the heart. This leads to lower levels of $\mathrm{BP}$ and $\mathrm{HR}$ at rest and abnormal $\mathrm{CV}$ responses to physiological stressors including exercise, which will be discussed later in this review.

Until recently, completeness of SCI was assessed by the residual motor and sensory functions with use of the American Spinal Injury Association (ASIA) Impairment Scale (AIS). ${ }^{23}$ However, this scale does not necessarily reflect the degree of damage to the ANS as there can be preservation of autonomic function in those with motor and sensorycomplete SCI. Conversely, there can be loss of autonomic function in those with motor and sensory incomplete SCI. ${ }^{24-26}$ The need for an evaluation and documentation of residual autonomic functions following SCI has been recognized by clinicians and scientist worldwide. As a result, a new system to document the impact of SCI on autonomic function was recently proposed. ${ }^{27}$

\section{The current Paralympic classification and its implications for $\mathrm{SCl}$ athletes with ANS dysfunction}

The term "classification" for participants in Paralympic events refers to the "process by which athletes are assessed by reference to the impact of impairment on their ability to compete in... (a specific sporting event) ${ }^{\prime \prime}{ }^{1}$ Classification is undertaken to allow for fair competition and to ensure that the strategies, skills and talent of the athlete determine 


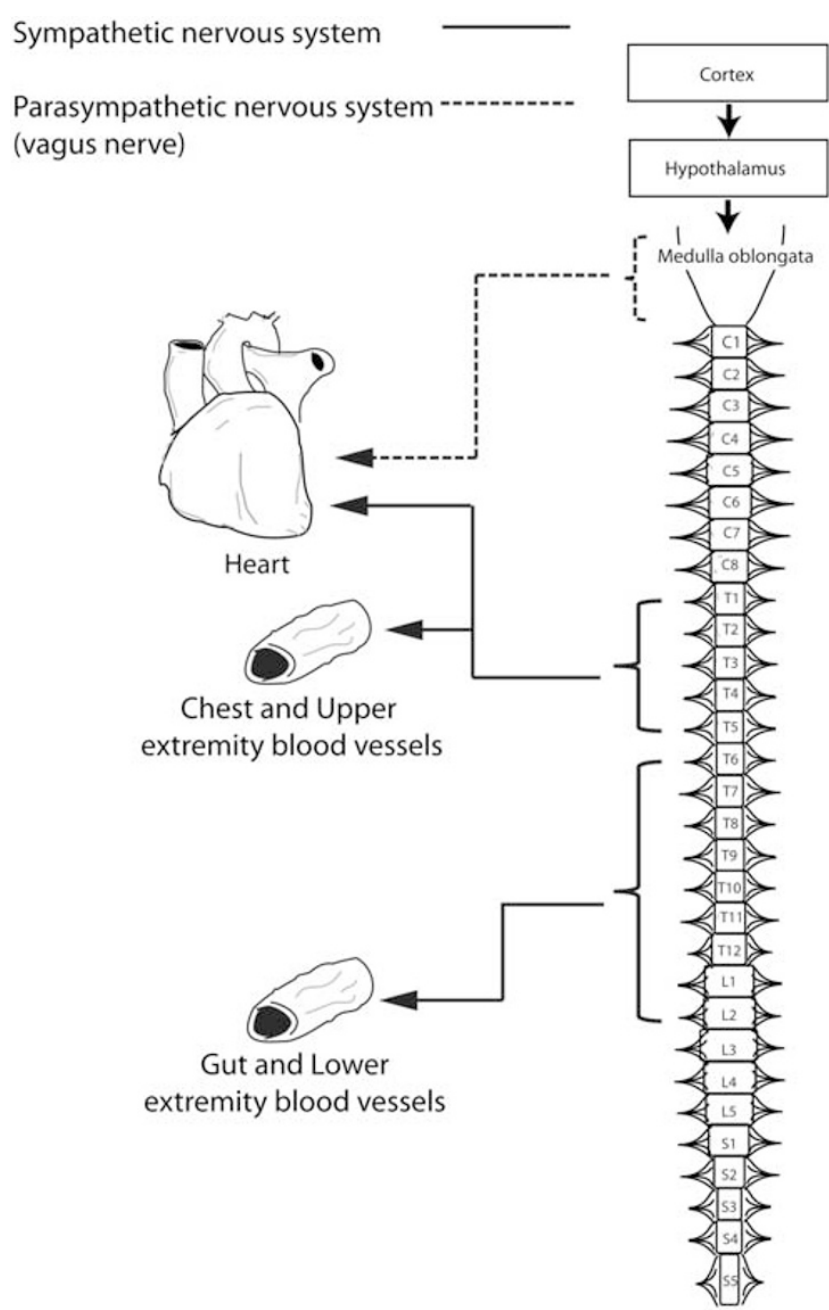

Figure 1 Schematic diagram of autonomic control of the CV system. The cerebral cortex and hypothalamus provide tonic and inhibitory inputs to the various nuclei within the medulla oblongata, where CV control is coordinated. Parasympathetic control of the heart occurs via the vagus nerve (vagus $\mathrm{N}$ ) that exits at the level of the brainstem (interrupted line). The preganglionic fibers of the vagus $\mathrm{N}$ then synapse with postganglionic parasympathetic neurons in ganglia on or near the target organ. Descending sympathetic pathways provide tonic control to spinal sympathetic preganglionic neurons (SPNs) involved in CV control. SPNs are found within the lateral horn of the spinal cord in segments T1-L2 and exit the spinal cord via the ventral root. They then synapse with postganglionic neurons located in the sympathetic chain (paravertebral ganglia). Finally, the sympathetic postganglionic neurons synapse with the target organs, heart and blood vessels (solid lines). The heart receives dual innervation, parasympathetic from the vagus $\mathrm{N}$ and sympathetic from the upper thoracic segments of the spinal cord (T1-T5). Blood vessels in the upper portion of the body receive sympathetic innervation from the T1 to T5 spinal sympathetic preganglionic neurons, whereas the vasculature beds in the gut and lower extremities are under the control of the more caudal T6-L2 spinal sympathetic preganglionic neurons. Afferent feedback for CV system from the central and peripheral baroreceptors and chemoreceptors is not shown.

competitive success, as opposed to their underlying impairment. ${ }^{1}$ In addition to the presence of a relevant impairment, it must be demonstrated that the impairment impacts sport performance.
Based on the most recent IPC Classification Code (2007), ${ }^{1}$ classification for Paralympians is performed by a classification panel. This panel allocates the athlete to a sport class, thereby determining eligibility to compete in Paralympic sports. The assessment is primarily comprised of four parts: (1) review of medical documentation of the impairment; (2) physical examination to establish the presence of an impairment, which allows the athlete to participate in the Paralympic sport; (3) technical assessment in which the classifiers observe the athlete perform sport-specific tasks in a simulated environment to determine to what extent performance is limited by the impairment; and (4) observation assessment in which the classifiers observe the athlete performing sport-specific skills during a training session or competition.

For the non-vision or non-intellectual impaired, the athlete population of interest for this review, every sporting event has a different classification. However, all the classifications have an exclusive focus on motor function of the arms, trunk and lower extremities. Some sports also consider deficits in skin sensation. ${ }^{1}$

Present classification does not take into account the ability to modulate the functions of heart, blood vessels and other sympathetically controlled organs due to underlying ANS impairment. ${ }^{1}$ For example, in the wheelchair racing classification there are four sport class profiles, which are based on loss of strength in the arms, trunk and legs as assessed during the physical examination session. ${ }^{2}$ The technical and observation assessments examine how these impairments affect leg positioning, arm function and trunk stability in the sport. The sport class is used to adjust for the level of impairment of the athlete to allow comparison across competitors.

Using the classification for wheelchair basketball as an example of a team sport, each athlete is assigned a score from 1 to 4.5 based on trunk, limb, and hand function. ${ }^{33}$ The higher the motor impairment, the lower the number. At any given time in a game, the five players on court must not exceed a total of 14 points. This ensures a mix of individuals with motor impairments that are comparable across teams during the competition.

Within the actual classification systems, individuals with high-level SCI whom we know are at risk for ANS dysregulation are grouped into the same category as individuals with similar motor function but intact ANS regulation. Therefore, the effect of SCI on exercise responses in SCI athletes with impaired ANS compared with those with intact ANS must be explored.

\section{Effect of $\mathrm{SCl}$ on elite athletes' exercise performance}

The important components of $\mathrm{CV}$ control needed for exercise performance include appropriate BP and HR regulation and reflex response to exercise. ${ }^{29,34}$ This requires appropriate sympathovagal balance in regulation of the $\mathrm{CV}$ system, resulting in sufficient blood redistribution to the muscles during exercise. This is possible only with proper sympathetic control of the cardiac and regional blood vessels 
in addition to skeletal muscle pump activity. ${ }^{4,13,34}$ Furthermore, appropriate catecholamine release by peripheral sympathetic nerves is also paramount for maintaining good muscle activity during exercise. ${ }^{35}$ Other systems also influence exercise performance, including respiration, muscular function, temperature and sweat regulation. ${ }^{4,34}$ Unfortunately, all of these systems, including autonomic control of the CV system, are commonly affected by SCI and the extent of dysfunction of these systems depends on the level and severity of the injury. ${ }^{24,28,36,37}$

The current Paralympic athlete classification emphasizes motor function and does not take into account CV dysfunction or other systems under autonomic control. In order to reconsider the current classification system, we need to take a careful look at what CV dysfunction is experienced by SCI athletes and how it could affect exercise performance.

It is well known that following SCI, baseline resting BP is inversely correlated with the level of injury; individuals with high level SCI have resting systolic BPs on average 15-20 mm Hg lower than able-bodied individuals (Figure 2). ${ }^{13,26}$ A similar pattern can also be seen with HR,
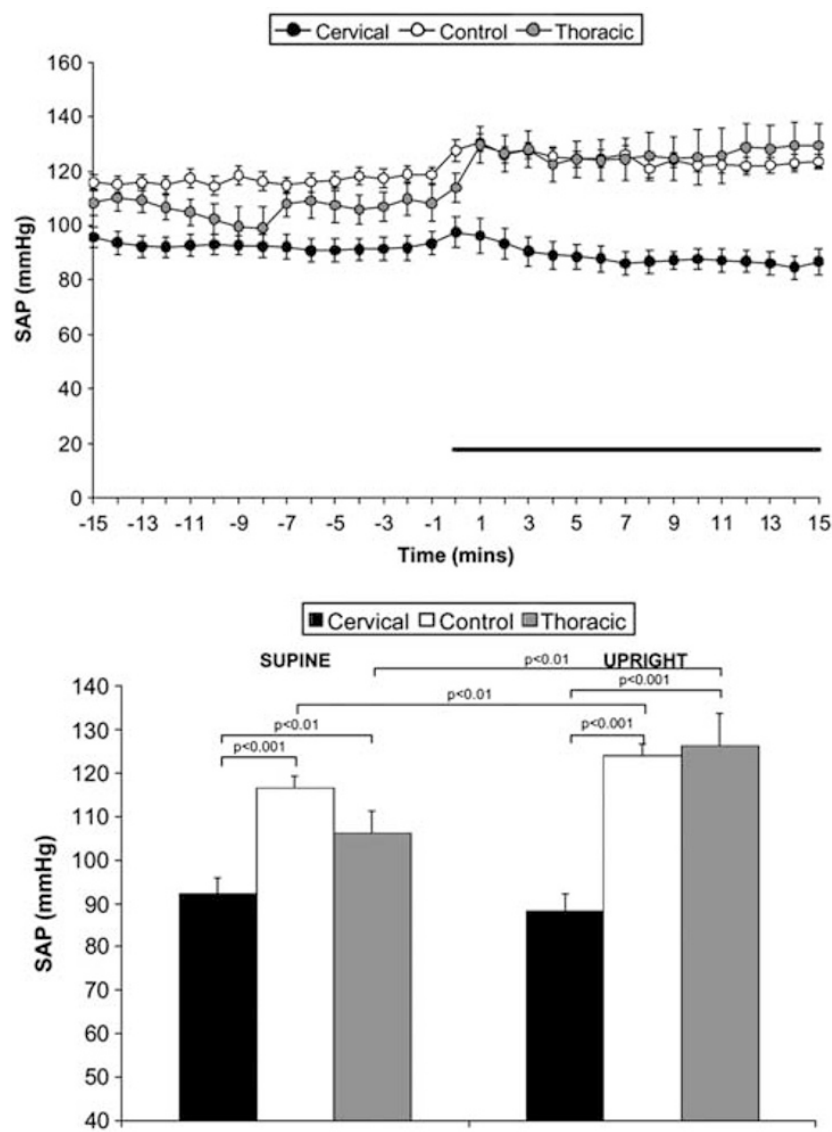

Figure 2 Systolic arterial pressure (SAP) responses to the orthostatic stress in individuals with cervical, thoracic $\mathrm{SCl}$ and able-bodied volunteers. The upper panel shows mean data for each group, every minute, for the duration of the test; the horizontal line denotes the upright seated portion of the test. The lower panel shows the average values of SAP for each group when supine and upright. Supine SAP was lower in cervical $\mathrm{SCl}$ than the other two groups $(P<0.01)$. When upright, SAP decreased in $50 \%$ of cervical SCl $(-15 \pm 3 \mathrm{~mm} \mathrm{Hg}$, $P<0.05$ ) (with permission from Claydon and Krassioukov ${ }^{26}$ ). resulting in a stroke volume that is lower in individuals with higher levels of SCI. ${ }^{26,38}$ There is also peripheral pooling of blood in the lower extremities due to decreased sympathetic tone, in addition to altered muscle pump activity of the skeletal muscles below the level of injury. ${ }^{39}$ In general, the most commonly described phenomenon in response to exercise in high-level SCI individuals is poor HR and BP response. Furthermore, individuals with SCI also are prone to develop a post-exercise-induced hypotension that could further affect their performance (Figure 3). ${ }^{40}$

In the able-bodied population, higher fitness levels have been related to improved autonomic CV control, and conversely, physical inactivity has been associated with reduced autonomic CV tone. ${ }^{41,42}$ Also, a low resting $\mathrm{HR}$ and high vagal tone have been reported in endurancetrained able-bodied athletes when compared with sedentary able-bodied individuals, suggesting physical activity is a
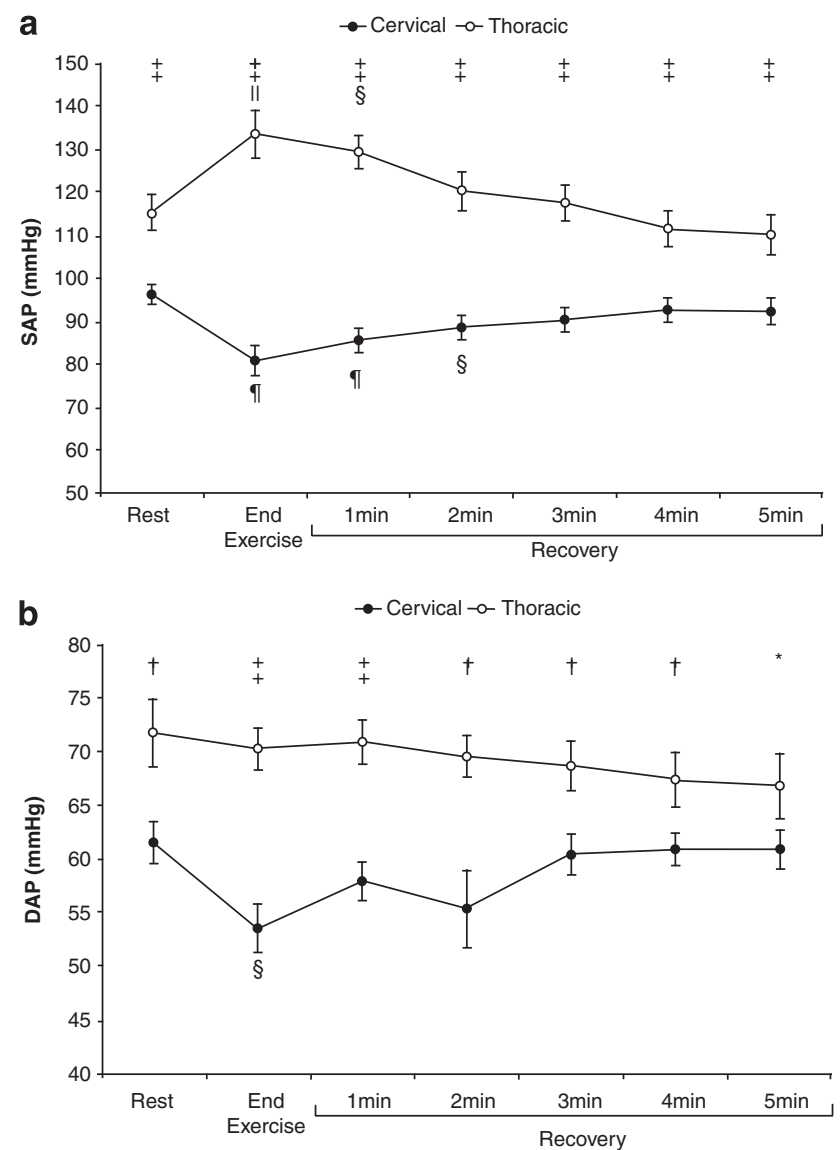

Figure 3 Systolic (SAP, a) and diastolic (DAP, b) arterial pressure responses to exercise. Resting seated SAP and DAP were significantly higher in individuals with thoracic than those with cervical SCI. After exercise, SAP was increased in individuals with thoracic $\mathrm{SCl}$, but was decreased in those with cervical $\mathrm{SCl}$. After exercise, DAP was unchanged in individuals with thoracic level $\mathrm{SCl}$, but was decreased in those with cervical $\mathrm{SCl}$. During the recovery from exercise, BPs began to return to the resting levels in both groups, but were consistently elevated in individuals with thoracic compared with cervical $\mathrm{SCl}$. ${ }^{\star} P<0.05 ;{ }^{\dagger} P<0.01 ;{ }^{\ddagger} P<0.001$ cervical versus thoracic; ${ }^{\$} P<0.05 ;{ }^{\uparrow} P<0.001$ within-group comparison against the resting condition. Note the change in scale in the lower panel (with permission from Claydon et al. $^{40}$ ). 
modulator of resting vagosympathetic cardiac control. ${ }^{43,44}$ Athletes with SCI have also demonstrated some ability to improve CV modulation through exercise, ${ }^{44,45}$ although not to the extent of athletes with intact ANS. ${ }^{46,47}$

To address the question as to how ANS dysfunction relates to Paralympic classification, it is important to look specifically at the response to exercise in SCI athletes. Hence, the studies chosen for this manuscript were selected for individuals with high levels of fitness, either determined by the study author based on number of hours per week of training, or due to participation in a national or international level sport.

These studies consistently show that SCI athletes with injuries above T6 have lower maximal HR (due to altered sympathetic tone and lower catecholamine release), ${ }^{4-51}$ lower maximal oxygen uptake $\left(\mathrm{VO}_{2}\right)^{48,50}$ and lower peak power $(\mathrm{W})^{48,49}$ in response to submaximal and maximal exercise in comparison with athletes with lower levels of SCI and athletes with intact ANS. It is also known that athletes with cervical SCI have smaller heart volumes in comparison with able-bodied athletes with similar levels of training and body size. ${ }^{52}$ Atrophy of cardiac muscle following high-level SCI is thought to be due to a combination of factors including, (1) impaired sympathetic drive to the heart and (2) decreased venous return from lack of sympathetic vasoconstriction and muscle paralysis below the lesion resulting in disturbed redistribution of blood flow and venous pooling. ${ }^{53,54}$ Consequently, stroke volume and cardiac output are decreased, compromising $\mathrm{VO}_{2}$ and oxygen delivery to exercising muscles. ${ }^{4}$ It has also been observed that athletes with cervical SCI have lower maximal $\mathrm{HR}$ and peak $\mathrm{VO}_{2}$ in response to exercise compared with athletes with injury between $\mathrm{T} 1$ and $\mathrm{T} 6 .^{50}$

Conversely, SCI athletes with injury below T6 have intact autonomic control of the heart and are, therefore, able to modulate $\mathrm{HR}$ in response to exercise. ${ }^{48,55,56}$ However, sympathetic innervation to blood vessels below the level of injury can still be impaired, resulting in a smaller stroke volume due to decreased venous return to the heart from blood pooling in the peripheries. ${ }^{48,57}$ As a result, SCI athletes with injury below T6 compensate for a lower stroke volume with higher HR responses during exercise compared with their able-bodied counterparts, and are able to achieve a comparable cardiac output to athletes without SCI. ${ }^{55,58,59}$ Impaired regulation of blood vessels below the mid-thoracic lesion can also lead to lower BPs in the exercise recovery phase. ${ }^{58}$

In addition to the level of injury there is limited evidence in the SCI athlete population that completeness of injury also affects CV responses during exercise. Data from our laboratory demonstrates that there are independent interactions between preservation of palmar sympathetic skin responses (suggestive of incomplete autonomic injury) and the upright mean BP $(r=0.5887, P=0.005)$ during the orthostatic stress in individuals with cervical SCI. ${ }^{26}$ Goosey-Tolfrey et al. ${ }^{60}$ in a small group of athletes with cervical SCI demonstrated lower maximal HR, lower peak $\mathrm{VO}_{2}$ and lower peak power in individuals with complete lesions compared with those with incomplete lesions. Given our present understanding of the impact of ANS control on $\mathrm{CV}$ function we have to be cautious with interpretation of results when investigators group the results from AIScomplete and -incomplete injuries together for analysis.

In summary, individuals with high-level SCI, including high-level performing athletes, have altered autonomic control of CV system that can impact exercise performance. With the current Paralympic classification, athletes with intact versus impaired ANS function, but similar motor function, are placed within the same sporting class. This creates the potential for an uneven playing field between Paralympic athletes and the application of inappropriate strategies to accommodate for a loss of (physiological) function. Boosting, or voluntarily induced $\mathrm{AD}$, is a practice unique to athletes with high-level SCI, and is sometimes used by this population to improve exercise performance. ${ }^{7}$

\section{Boosting, the intentional induction of $A D$}

Experimental and clinical studies demonstrate that $\mathrm{CV}$ control in individuals with SCI are associated with unopposed parasympathetic regulation and sympathetic hypoactivity causing lower levels of $\mathrm{BP}$ and $\mathrm{HR}$ at rest and in response to physiological stressors including exercise. Conversely, physiological stimuli that are well tolerated in able-bodied individuals can become triggers for $\mathrm{AD}$, characterized by uninhibited sympathetic activity generated by spinal cord circuits following high-level SCI (Figure 4). ${ }^{30,61}$ The unstable BP control with episodes of dangerously high $\mathrm{BP}$ or cardiac arrhythmias resulting from $\mathrm{AD}$ can occur involuntarily with both noxious and non-noxious stimuli, and is defined as the elevation of systolic BP by at least $20 \mathrm{~mm} \mathrm{Hg}$ from baseline. ${ }^{11,62}$ Boosting, by comparison, is the intentional induction of AD by a SCI athlete during training or competition. ${ }^{8}$ There are anecdotal reports of various methods of boosting during competition, including sitting on the scrotum, clamping of the foley catheter and breaking the big toe.

Only three studies specifically observe CV responses of SCI athletes in boosted versus unboosted states. Wheeler et al. ${ }^{10}$ and Burnham et al., ${ }^{7}$ both used the same eight high-level SCI athletes who were elite tetraplegic road racers. In both studies, these athletes were observed when boosting and not boosting while performing a $7.5 \mathrm{~km}$ race and during a graded arm exercise test to maximal effort in a supervised environment. Schmid et al. ${ }^{9}$ studied six elite high-level SCI athletes: three wheelchair racers and three wheelchair rugby players. These six athletes were observed performing a graded arm exercise test to maximal effort using a wheelchair ergometer. In each study, boosting was achieved by either increasing fluid intake before the event in order to over distend the bladder, or by prolonged sitting in the wheelchair before the exercise protocol.

During the graded arm exercise, Burnham and Wheeler found that, when boosted, athletes experienced a significant increase in peak $\mathrm{HR}$, peak BP, circulating norepinephrine levels, maximal $\mathrm{VO}_{2}$ and peak $\mathrm{W}$ (Table 1 ). However, despite the increase in peak $\mathrm{HR}$, cardiac output was unchanged 

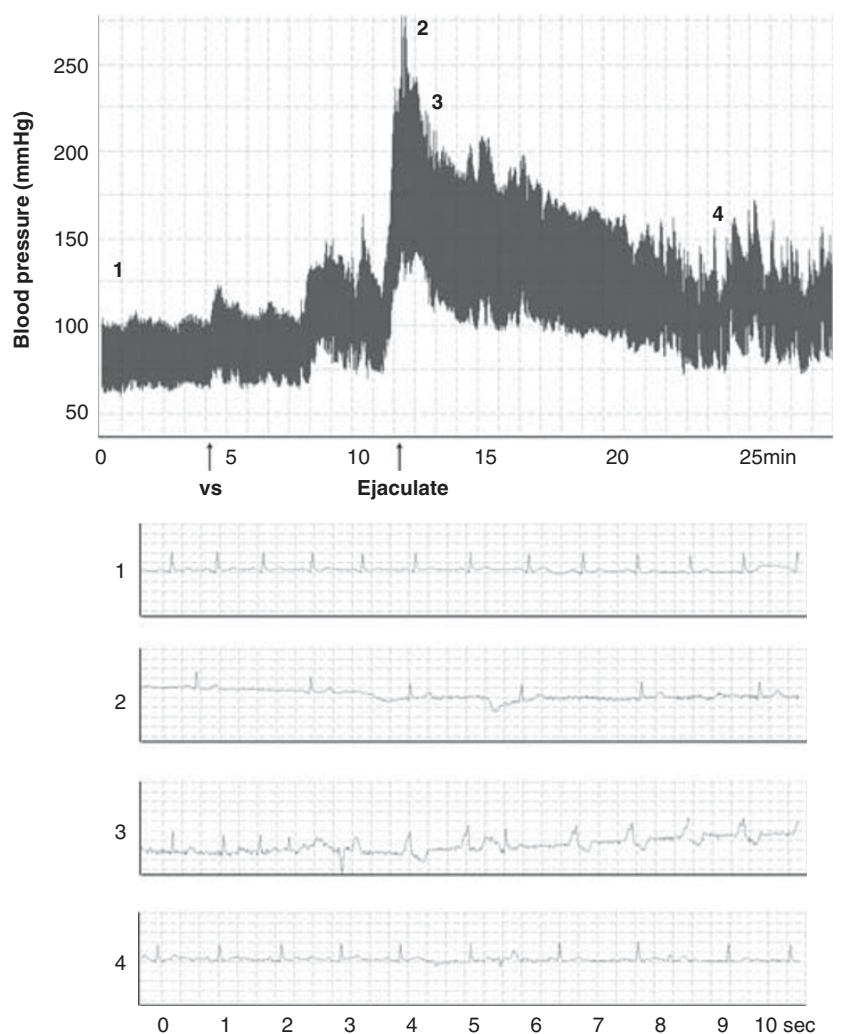

Figure 4 Changes in BP and HR in men with cervical spinal cord injury (C7 AIS (American Spinal Injury Association Impairment Scale) B) during the vibrostimulation (VS) procedure for sperm retrieval. BP (using a finger cuff) and three lead electrocardiogram (ECG) were recorded continuously (Finometer Pro Finapres Medical Systems, Amsterdam, Netherlands; Powerlab, ADInstruments, Bella Vista, Australia) during the procedure. BP (top diagram) during the procedure and four $10 \mathrm{~s}$ samples of ECG recorded during different periods of the procedure (bottom diagrams) are shown (1 - at rest; 2-at ejaculation; 3-3 min following ejaculation; 4-20 min following ejaculation). Before VS (rest, recording 1) there was relative hypotension $(100 / 65 \mathrm{~mm} \mathrm{Hg})$ with a regular HR of $78 \mathrm{bpm}$. With initiation of VS (first arrow) there was a gradual increase in arterial BP suggestive of a typical episode of AD. Finally, at the time of ejaculation arterial BP surged to $280 / 150 \mathrm{~mm} \mathrm{Hg}$ accompanied by bradycardia at $38 \mathrm{bpm}$ (recording 2) and a short run of premature ventricular contractions (PVCs) was observed $3 \mathrm{~min}$ following ejaculation (recording 3). At $15 \mathrm{~min}$ following ejaculation arterial BP was still slightly elevated $(130 \mathrm{~mm} \mathrm{Hg}, \mathrm{HR} 66 \mathrm{bpm}$, recordings 4). During the next 20-25 min arterial BP and HR gradually returned to resting values. This episode of $A D$ was accompanied by significant spasms in the upper and lower extremities, profuse sweating on the forehead and neck, and piloerection on the forearms. Interestingly, during this episode of $A D$ the patient reported only a mild headache (personal observations) (with permission from Krassioukov ${ }^{61}$ ).

because of the significantly lower stroke volumes that occurred in the boosted state. In addition, there were no boosting-related changes seen in metabolism, as represented by levels of free fatty acids, glucose and lactate concentration. With respect to exercise performance, during the $7.5 \mathrm{~km}$ wheelchair race there was a significant decrease in racing time in the boosted $(22.6 \pm 6.6 \mathrm{~min})$ compared with the unboosted state $(25.6 \pm 9 \mathrm{~min})$, which translated to a mean performance increase of $9.2 \%{ }^{7}$ There was also a lower rating of perceived exertion by the athletes during the boosted state.
These athletes also filled out a questionnaire on the practice of boosting. ${ }^{7,10}$ All of the athletes reported having used boosting to improve performance during competition. Subjectively, they felt that boosting increased arm strength and endurance, decreased arm stiffness, improved breathing, and increased alertness and aggressiveness. Half of the individuals also reported that they could 'boost too much' and $5 / 8$ felt they could not boost predictably. Side effects frequently experienced with boosting included headaches and excessive shivering and sweating. All of the athletes believed that the practice of boosting for the purpose of performance enhancement is widespread among competitive high-level SCI athletes.

In comparison with these eight tetraplegic wheelchair racers, all of the high-level SCI athletes in Schmid et al. $(n=6)$ denied using boosting to improve performance during a race. ${ }^{9}$ However, many had experienced side effects of AD during training, and all had heard of boosting. In these athletes, responses to exercise during the boosted state in comparison with the unboosted state also showed that there was a significant increase in peak $\mathrm{HR}$, peak BP, circulating norepinephrine levels, maximal $\mathrm{VO}_{2}$ and peak $\mathrm{W}$ (Figure 5). These changes are consistent with those demonstrated in the studies by Wheeler et al. and Burnham et al. Unfortunately, none of the three studies had a control group with similar level of lesion and training but with intact sympathetic nervous system control to determine how much boosting compensated for the impact of autonomic dysregulation on exercise performance.

Blood pressure responses in Burnham et al. and Schmid et al. were significantly elevated in the boosted state, reaching as high as over $200 \mathrm{~mm} \mathrm{Hg}$ systolic (Table 1). ${ }^{9,10}$ Although limited, there is data showing improved performance with boosting in high-level SCI athletes, therefore it is very important to be aware of the potential dangers of uncontrolled AD. There have been no documented consequences directly linked to boosting in competition to date. However, there are numerous reports of significant consequences in clinical situations, including myocardial infarction and seizures. ${ }^{15-18,63}$

Due to potential health risks, the IPC and other governing bodies have struggled with how to address the issue of boosting. ${ }^{64}$ Although boosting could be used to enhance performance, significant controversy arose as to whether boosting should be considered as a form of doping, mainly because doping at the time was considered to be the administration of or use of any substance foreign to the athlete's body, or of any physiological substance taken in abnormal quantity or taken by abnormal route of entry in to the body with the sole intention of artificially increasing performance in competition' ${ }^{64}$ Adding to the controversy is the difficulty in proving whether episodes of high BP identified during competition are intentionally induced, as spontaneous episodes of $\mathrm{AD}$ are a common occurrence in individuals with high level SCI. ${ }^{65}$

Concern for the potential health risks due to uncontrolled high levels of BP led the IPC to officially ban boosting in the Paralympic movement for health safety reasons. ${ }^{19}$ Screening for AD in athletes before the competition was first instituted 
Table 1 Boosting safety: BP and body temperature response during $7.5 \mathrm{~km}$ simulated race in elite tetraplegic athletes

\begin{tabular}{|c|c|c|c|c|c|c|}
\hline & \multicolumn{2}{|c|}{ Pre-race } & \multicolumn{2}{|c|}{ Mid-race } & \multicolumn{2}{|c|}{ Post-race } \\
\hline & Boosted & Unboosted & Boosted & Unboosted & Boosted & Unboosted \\
\hline \multicolumn{7}{|l|}{ Blood pressure $(\mathrm{mm} \mathrm{Hg})$} \\
\hline Systolic & $155(20)$ & $106(16)^{a}$ & $138(23)$ & $105(18)^{a}$ & $132(32)$ & $99(19)^{a}$ \\
\hline Diastolic & $93(22)$ & $61(11)^{a}$ & 78 (18) & $59(6)$ & $62(21)$ & $55(8)$ \\
\hline Mean arterial pressure & $114(19)$ & $76(9)^{a}$ & 98 (19) & $74(7)^{a}$ & $85(23)$ & $69(8)$ \\
\hline Temperature $\left({ }^{\circ} \mathrm{C}\right)$ & $35.3(0.7)$ & $35.7(0.6)$ & & & $36.6(0.7)$ & $36.4(0.7)$ \\
\hline
\end{tabular}

Abbreviation: BP, blood pressure.

There was significant increase in BP during boosted states, which were associated with improvement in performance during racing (measured as time to complete race, with permission from Burnham et $a l^{7}$ ).

Numerals within parentheses indicate s.d.

${ }^{\mathrm{a}} \mathrm{P}<0.05$.

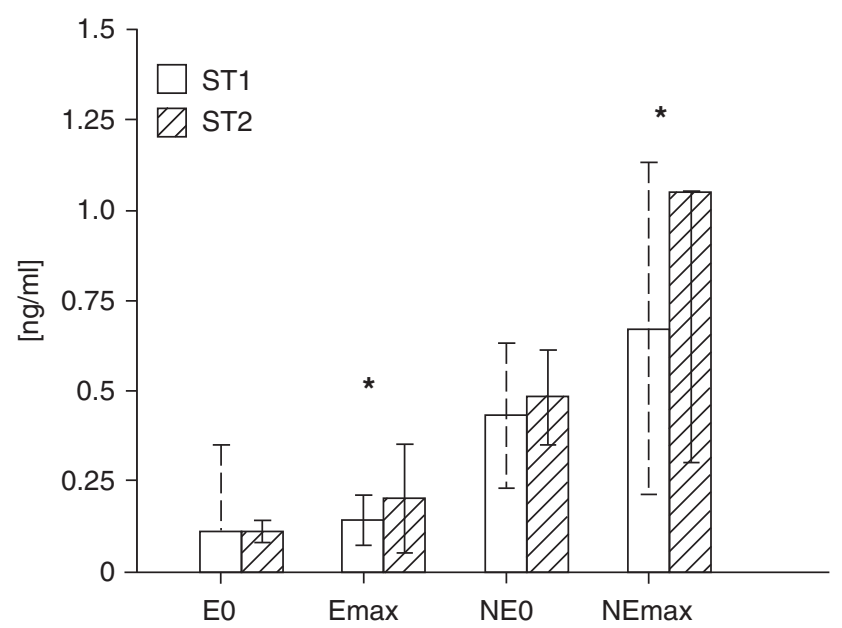

Figure 5 Epinephrine and norepinephrine levels at rest (E0, NE0) and maximum exercise (Emax, NEmax) in the incremental wheelchair exercise test without (ST1) and with (ST2) AD. Although no significant difference was found for epinephrine and norepinephrine at rest in both groups, there was a significantly higher value for epinephrine $\left(0.20 \pm 0.15\right.$ vs $\left.0.14 \pm 0.07 \mathrm{ng} \mathrm{ml}^{-1}\right)$ and norepinephrine $\left(1.05 \pm 0.75\right.$ vs $\left.0.67 \pm 0.46 \mathrm{ng} \mathrm{ml}^{-1},{ }^{*} P<0.05\right)$ after exercise with AD (ST2) (with permission from Schmid et al. ${ }^{56}$ ).

in the 1996 Atlanta Summer Paralympic Games and has continued since. ${ }^{64}$ To screen for AD, IPC medical staff check athletes for signs of $\mathrm{AD}$ before a race or event, and take BP measurements. If the BP is significantly elevated ( $>180 \mathrm{~mm} \mathrm{Hg}$ systolic), the athlete is given time to rest and attempt to lower their BP, which is subsequently re-measured. ${ }^{19}$

At the 2008 Beijing Summer Paralympic games, Bhambani et al. examined the perception of boosting using a selfreported questionnaire in Paralympians with SCI. ${ }^{20}$ Of the 99 participants, a majority were involved in wheelchair rugby (54.2\%) and familiar with the term boosting (54\%). Only 10 participants admitted to boosting (wheelchair rugby (55.5\%), wheelchair marathon (22.2\%) and long distance racing $(22.2 \%)$ ). Individuals who responded positively on use of boosting during the competition had SCI at T6 or above $(80 \%)$. The results from this study show that boosting continues to be practiced by high-level SCI athletes despite the recognized health risks and IPC ban.

\section{Conclusion}

Athletes with high-level SCI and resulting ANS dysfunction present a unique challenge for a fair classification system for athletes who wish to participate in the Paralympic games. Complexity and variations in autonomic disorders make this process very challenging. Presently, classes are determined by a variety of processes that may include a physical and technical assessment, and observation in and out of competition. By focusing on assessment of motor function of Paralympians, we may be placing SCI athletes with significant ANS abnormalities at a disadvantage to competitors with similar motor function but preserved autonomic control. Additionally, the potential use of boosting by highlevel SCI athletes in spite of the ban by the IPC further emphasizes the need for a review of the current approach. The IPC recognizes that the present classification system is not the gold standard and that further research is required to create a classification system that is more evidence-based. ${ }^{1}$ Given that the principle of fair play is important in Paralympic sport, this issue needs to be addressed.

In order to determine whether Paralympic classification should take autonomic dysfunction into account, a simple, easily implementable standardized autonomic assessment of athletes with SCI needs to be established. Additionally, this assessment should be used to reliably compare athletes with or without ANS dysfunction, thereby enabling further research into the isolated effect of ANS dysfunction on sporting performance. Finally, researchers who are studying individuals with SCI, and who have CV parameters as their outcomes, should ensure a homogenous study group by the presence or absence of ANS function in addition to level of lesion so as to eliminate the potential for confounding variables.

\section{Conflict of interest}

The authors declare no conflict of interest. 


\section{Acknowledgements}

We would like to acknowledge Margaret Mills, Bill Mills, Dr Peter van de Vliet, Dr Heather Finlayson and Dr Andrew Travlos for their support during the preparation of this manuscript. Dr P Mills - Disability Health Research Network fellowship, Dr A Krassioukov-Heart and Stroke Foundation of Canada, Christopher and Dana Reeve Foundation, Rick Hansen Foundation, Craig $\mathrm{H}$ Neilsen Foundation and Disability Health Research Network.

\section{References}

1 International Paralympic Committee. IPC classification code and international standards, Available at: http://www.paralympic.org/ export/sites/default/IPC/IPC_Handbook/Section_2/2008_2_Classi fication_Code6.pdf (accessed January 3, 2010).

2 International Paralympic Committee. Position statement on background and scientific rationale for classification in paralympic sport. Chapter 4.4 IPC Handbook. International Paralympic Committee, Bonn, Germany, Available at: http://www.paralympic. org/export/sites/default/IPC/IPC_Handbook/Section_2/Sec_ii_chapter_ 4.4_Position_Statement_on_Classification.pdf (accessed January 3, 2010).

3 Claus-Walker J, Halstead LS. Metabolic and endocrine changes in spinal cord injury: II (section 1). Consequences of partial decentralization of the autonomic nervous system. Arch Phys Med Rehabil 1982; 63: 569-575.

4 Figoni SF. Exercise responses and quadriplegia. Med Sci Sports Exerc 1993; 25: 433-441.

5 Garstang SV, Miller-Smith SA. Autonomic nervous system dysfunction after spinal cord injury. Phys Med Rehabil Clin N Am 2007; 18: 275-296.

6 Gondim FA, Lopes Jr AC, Oliveira GR, Rodrigues CL, Leal PR, Santos AA et al. Cardiovascular control after spinal cord injury. Curr Vasc Pharmacol 2004; 2: 71-79.

7 Burnham R, Wheeler G, Bhanbhani Y, Belanger M, Eriksson P, Steadward R. Intentional induction of autonomic dysreflexia among quadriplegic athletes for performance enhancement: efficacy, safety, and mechanism of action. Clin J Sport Med 1994; 4: $1-10$.

8 Webborn AD. 'Boosting' performance in disability sport. Br J Sports Med 1999; 33: 74-75.

9 Schmid A, Schmidt-Trucksass A, Huonker M, König D, Eisenbarth I, Sauerwein $\mathrm{H}$ et al. Catecholamines response of high performance wheelchair athletes at rest and during exercise with autonomic dysreflexia. Int J Sports Med 2001; 22: 2-7.

10 Wheeler G, Cumming D, Burnham R, Maclean I, Sloley BD, Bhambhani $\mathrm{Y}$ et al. Testosterone, cortisol and catecholamine responses to exercise stress and autonomic dysreflexia in elite quadriplegic athletes. Paraplegia 1994; 32: 292-299.

11 Karlsson AK. Autonomic dysreflexia. Spinal Cord 1999; 37: 383-391.

12 Kewalramani LS. Autonomic dysreflexia in traumatic myelopathy. Am J Phys Med 1980; 59: 1-21.

13 Krassioukov A, Claydon VE. The clinical problems in cardiovascular control following spinal cord injury: an overview. Prog Brain Res 2006; 152: 223-229.

14 Eltorai I, Kim R, Vulpe M, Kasravi H, Ho W. Fatal cerebral hemorrhage due to autonomic dysreflexia in a tetraplegic patient: case report and review. Paraplegia 1992; 30: 355-360.

15 Yarkony GM, Katz RT, Wu Y. Seizures secondary to autonomic dysreflexia. Arch Phys Med Rehabil 1986; 67: 834-835.

16 Ho CP, Krassioukov AV. Autonomic dysreflexia and myocardial ischemia. Spinal Cord 2010; 48: 714-715.

17 Pine ZM, Miller SD, Alonso JA. Atrial fibrillation associated with autonomic dysreflexia. Am J Phys Med Rehabil 1991; 70: 271-273.

18 Valles M, Benito J, Portell E, Vidal J. Cerebral hemorrhage due to autonomic dysreflexia in a spinal cord injury patient. Spinal Cord 2005; 43: 738-740.
19 International Paralympic Committee. Position statement on autonomic dysreflexia and boosting. Chapter 4.3 IPC Handbook. International Paralympic Committee, Bonn, Germany, Available at: http://www.paralympic.org/export/sites/default/IPC/IPC_ Handbook/Section_2/Sec_ii_chapter_4.3_Position_Statement_on_ Autonomic_Dysreflexia_and_Boosting.pdf (accessed January 3, 2010)

20 Bhambhani Y, Mactavish J, Warren S, Thompson W, Webborn A, Bressan $\mathrm{E}$ et al. Boosting in athletes with high level spinal cord injury: incidence, knowledge and attitudes of athletes in paralympic sport. Available at: http://www.wada-ama.org/ rtecontent/document/Bhambhani_final_report_2009.PDF (accessed March 10, 2010).

21 Bravo G, Guizar-Sahagun G, Ibarra A, Centurion D, Villalon CM. Cardiovascular alterations after spinal cord injury: an overview. Curr Med Chem Cardiovasc Hematol Agents 2004; 2: 133-148.

22 Krassioukov A. Which pathways must be spared in the injured human spinal cord to retain cardiovascular control? Prog Brain Res 2006; 152: 39-47.

23 Marino RJ, Barros T, Biering-Sorensen F, Burns SP, Donovan WH, Graves $\mathrm{DE}$ et al. International standards for neurological classification of spinal cord injury. J Spinal Cord Med 2003; 26: S50-S56.

24 Curt A, Nitsche B, Rodic B, Schurch B, Dietz V. Assessment of autonomic dysreflexia in patients with spinal cord injury. J Neurol Neurosurg Psychiatry 1997; 62: 473-477.

25 Curt A, Weinhardt C, Dietz V. Significance of sympathetic skin response in the assessment of autonomic failure in patients with spinal cord injury. J Auton Nerv Syst 1996; 61: 175-180.

26 Claydon VE, Krassioukov AV. Orthostatic hypotension and autonomic pathways after spinal cord injury. I Neurotrauma 2006; 23: 1713-1725.

27 Alexander MS, Biering-Sorensen F, Bodner D, Brackett NL, Cardenas D, Charlifue $\mathrm{S}$ et al. International standards to document remaining autonomic function after spinal cord injury. Spinal Cord 2009; 47: 36-43.

28 Curt A, Weinhardt C, Dietz V. Significance of sympathetic skin response in the assessment of autonomic failure in patients with spinal cord injury. J Auton Nerv Syst 1996; 61: 175-180.

29 Teasell RW, Arnold JM, Krassioukov A, Delaney GA. Cardiovascular consequences of loss of supraspinal control of the sympathetic nervous system after spinal cord injury. Arch Phys Med Rehabil 2000; 81: 506-516.

30 Krassioukov AV, Johns DG, Schramm LP. Sensitivity of sympathetically correlated spinal interneurons, renal sympathetic nerve activity, and arterial pressure to somatic and visceral stimuli after chronic spinal injury. J Neurotrauma 2002; 19: 1521-1529.

31 Krassioukov AV, Bunge RP, Pucket WR, Bygrave MA. The changes in human spinal sympathetic preganglionic neurons after spinal cord injury. Spinal Cord 1999; 37: 6-13.

32 Krassioukov AV, Weaver LC. Reflex and morphological changes in spinal preganglionic neurons after cord injury in rats. Clin Exp Hypertens (New York) 1995; 17: 361-373.

33 International Wheelchair Basketball Federation Player Classification Commission. A Guide to the IWBF Functional Classification System for Wheelchair Basketball Players, Available at: http:// www.aqsfr.qc.ca/sport/basket/ClassificationManual_2004_final. pdf. (accessed January 10, 2010).

34 Sutlive VH, Neujahr E, Royse R, Stanich M. Intrinsic dynamics of persons with spinal cord injury autonomic nervous system constraints. Clin Kinesiol 1999; 53: 4-10.

35 Warburton DE, Glendhill N, Quinney A. The effects of changes in musculoskeletal fitness on health. Can J Appl Physiol 2001; 26: 161-216.

36 Dela F, Mohr T, Jensen CM, Haahr HL, Secher $\mathrm{NH}_{\text {, }}$ Biering-Sorensen $\mathrm{F}$ et al. Cardiovascular control during exercise: insights from spinal cord-injured humans. Circulation 2003; 107: 2127-2133.

37 Krassioukov AV, Karlsson A, Wecht JM, Wuermser LA, Mathias CJ, Marino RJ. Assessment of autonomic dysfunction following spinal cord injury: rationale for additions to international standards for neurological assessment. J Rehabil Res Dev 2007; 44: 103-112. 
38 DiPette D, Gavras I, North W. Vasopressin response to hyperosmotic stimulus: blood pressure effect in normal subjects and patients with impaired sympathetic system. Clin Exp HypertensPart A Theory Pract 1984; 6: 851-861.

39 Hopman MT, Groothuis JT, Flendrie M, Gerrits KH, Houtman S. Increased vascular resistance in paralyzed legs after spinal cord injury is reversible by training. J Appl Physiol 2002; 93: 1966-1972.

40 Claydon VE, Hol AT, Eng JJ, Krassioukov AV. Cardiovascular responses and postexercise hypotension after arm cycling exercise in subjects with spinal cord injury. Arch Phys Med Rehabil 2006; 87: 1106-1114.

41 Dixon EM, Kamath MV, McCartney N, Fallen EL. Neural regulation of heart rate variability in endurance athletes and sedentary controls. Cardiovasc Res 1992; 26: 713-719.

42 Yamamoto K, Miyachi M, Saitoh T, Yoshioka A, Onodera S. Effects of endurance training on resting and post-exercise cardiac autonomic control. Med Sci Sports Exerc 2001; 33: 1496-1502.

43 Wecht JM, De Meersman RE, Weir JP, Spungen AM, Bauman WA, Grimm DR. The effects of autonomic dysfunction and endurance training on cardiovascular control. Clin Auton Res 2001; 11: 29-34.

44 Otsuka Y, Shima N, Moritani T, Okuda K, Yabe K. Orthostatic influence on heart rate and blood pressure variability in trained persons with tetraplegia. Eur J Appl Physiol 2008; 104: 75-78.

45 Wecht JM, Marsico R, Weir JP, Spungen AM, Bauman WA, De Meersman RE. Autonomic recovery from peak arm exercise in fit and unfit individuals with paraplegia. Med Sci Sports Exerc 2006; 38: 1223-1228.

46 Schmid A, Huonker M, Stober P, Barturen JM, Schmidt-Trucksäss A, Dürr $\mathrm{H}$ et al. Physical performance and cardiovascular and metabolic adaptation of elite female wheelchair basketball players in wheelchair ergometry and in competition. Am J Phys Med Rehabil 1998; 77: 527-533.

47 Asayama K, Nakamura Y, Ogata H, Hatada K, Okuma H, Deguchi Y. Physical fitness of paraplegics in full wheelchair marathon racing. Paraplegia 1985; 23: 277-287.

48 Hopman MT, Oeseburg B, Binkhorst RA. Cardiovascular responses in persons with paraplegia to prolonged arm exercise and thermal stress. Med Sci Sports Exerc 1993; 25: 577-583.

49 Rimaud D, Calmels P, Roche F, Mongold JJ, Trudeau F, Devillard X. Effects of graduated compression stockings on cardiovascular and metabolic responses to exercise and exercise recovery in persons with spinal cord injury. Arch Phys Med Rehabil 2007; 88: 703-709.

50 Campbell IG, Williams C, Lakomy HK. Physiological and metabolic responses of wheelchair athletes in different racing classes to prolonged exercise. J Sports Sci 2004; 22: 449-456.
51 Barfield JP, Malone LA, Collins JM, Ruble SB. Disability type influences heart rate response during power wheelchair sport. Med Sci Sports Exerc 2005; 37: 718-723.

52 Schumacher YO, Ruthardt S, Schmidt M, Ahlgrim C, Roecker K, Pottgiesser T. Total haemoglobin mass but not cardiac volume adapts to long-term endurance exercise in highly trained spinal cord injured athletes. Eur J Appl Physiol 2009; 105: 779-785.

53 Kessler KM, Pina I, Green B, Burnett B, Laighold M, Bilsker M et al. Cardiovascular findings in quadriplegic and paraplegic patients and in normal subjects. Am J Cardiol 1986; 58: 525-530.

54 Nash MS, Bilsker S, Marcillo AE, Isaac SM, Botelho LA, Klose KJ et al. Reversal of adaptive left ventricular atrophy following electrically-stimulated exercise training in human tetraplegics. Paraplegia 1991; 29: 590-599.

55 Dawson B, Bridle J, Lockwood RJ. Thermoregulation of paraplegic and able bodied men during prolonged exercise in hot and cool climates. Paraplegia 1994; 32: 860-870.

56 Schmid A, Huonker M, Barturen JM, Stahl F, Schmidt-Trucksäss A, König D et al. Catecholamines, heart rate, and oxygen uptake during exercise in persons with spinal cord injury. J Appl Physiol 1998; 85: 635-641.

57 Hopman MT, Pistorius M, Kamerbeek IC, Binkhorst RA. Cardiac output in paraplegic subjects at high exercise intensities. Eur J Appl Physiol 1993; 66: 531-535.

58 Hopman MT, Kamerbeek IC, Pistorius M, Binkhorst RA. The effect of an anti-G suit on the maximal performance of individuals with paraplegia. Int J Sports Med 1993; 14: 357-361.

59 Hopman MT, Oeseburg B, Binkhorst RA. Cardiovascular responses in paraplegic subjects during arm exercise. Eur J Appl Physiol 1992; 65: 73-78.

60 Goosey-Tolfrey V, Castle P, Webborn N, Abel T. Aerobic capacity and peak power output of elite quadriplegic games players. Br J Sports Med 2006; 40: 684-687.

61 Krassioukov A. Autonomic function following cervical spinal cord injury. Respir Physiol Neurobiol 2009; 169: 157-164.

62 Garshick E, Kelley A, Cohen SA, Garrison A, Tun CG, Gagnon D et al. A prospective assessment of mortality in chronic spinal cord injury. Spinal Cord 2005; 43: 408-416.

63 Calder KB, Estores IM, Krassioukov A. Autonomic dysreflexia and associated acute neurogenic pulmonary edema in a patient with spinal cord injury: a case report and review of the literature. Spinal Cord 2009; 47: 423-425.

64 Legg D, Mason DS. Autonomic dysreflexia in wheelchair sport: a new game in the legal arena? Marq Sports $L J 1997 ; 8$ : 225-262.

65 International Paralympic Committee. IPC Anti-Doping Code, Available at: http://www.paralympic.org/export/sites/default/ IPC/IPC_Handbook/Section_2/2009_11_IPC_Anti-Doping_Code. pdf (accessed January 3, 2010). 